\title{
EXPERIÊNCIAS PARA A EdUCAÇÃo PATRIMONIAL VISANDO A EDUCAÇÃo RELIGIOSA
}

\author{
EXPERIENCES FOR PATRIMONIAL EDUCATION \\ FOR RELIGIOUS EDUCATION
}

\section{Taciane Jaluska* Sérgio Junqueira*}

\section{RESUMO}

A educação patrimonial voltada ao patrimônio religioso refere-se a um processo permanente de trabalho educacional centrado no espaço sagrado como fonte primária de conhecimento e enriquecimento individual e coletivo. A presente pesquisa pretende, por meio de um estudo de caso qualitativo, apresentar e realizar uma análise de três atividades de educação patrimonial realizadas em Curitiba, o roteiro 'Na Trilha do Sagrado', a 'visita guiada na Catedral Basílica Menor Nossa Senhora da Luz' e a 'visita noturna ao Cemitério Municipal de Curitiba' com a finalidade de compreender a importância da mediação no patrimônio cultural para a educação cultural e religiosa dos participantes. Os resultados da pesquisa apontam que a atividade de educação patrimonial em espaços voltados para o sagrado os aproximam da sociedade, auxiliam na preservação da memória, na criação de um sentimento de pertença e para criação de um elo entre passado e presente que podem auxiliar tanto na conservação desse bem quanto na difusão do conhecimento. Conclui-se que conhecer o diversificado patrimônio religioso da cidade permite ao indivíduo respeitar as diferentes manifestações culturais e a melhor compreendê-las, aliando assim conhecimento, ação e preservação.

Palavras-chave: Educação patrimonial. Espaços sagrados. Diversidade religiosa.

\section{ABSTRACT}

Patrimonial education focused on religious heritage refers to a permanent process of educational work centered on sacred space as the primary source of knowledge and individual and collective enrichment. The present research intends, through a qualitative case study, to present and carry out an analysis of three patrimonial education activities carried out in Curitiba, the script 'Na Trilha do Sagrado', the 'guided tour in the Cathedral Basilica Menor Nossa Senhora da Luz 'and the' nocturnal visit to the Municipal Cemetery of Curitiba 'in order to understand the importance of mediation in the cultural heritage for the cultural and religious education of the participants. The research results point out that the activity of heritage education in sacred spaces brings them closer to society, helps in preserving memory, creating a sense of belonging and creating a link between past and present that can help both in conservation of this good as in the diffusion of knowledge. It is concluded that knowing the diversified religious heritage of the city allows the individual to respect the different cultural manifestations and to better understand them, thus allying knowledge, action and preservation.

Keywords: Patrimonial education. Sacred spaces. Religious diversity.

\footnotetext{
* Doutora e mestra em Teologia pela Pontifícia Universidade Católica do Paraná. E-mail: taci_pl@hotmail.com

** Doutor e mestre em Ciências da Educação pela Pontifícia Universidade Salesiana de Roma. E-mail: srjunq@gmail.com
} 


\section{INTRODUÇÃO}

A partir do programa Concepções do Ensino Religioso - com a perspectiva de analisar o contínuo processo de construção da identidade do Ensino Religioso como componente curricular no cenário da educação brasileira e seus diferentes recursos e estratégias de ensino objetivando a integração com a formação docente - foram elaborados três projetos. Especificamente, o Recursos Didáticos foi iniciado no ano de 2017 com objetivo estabelecer os fundamentos de recursos de apoio aprendizagem tais como a Literatura e Espaço Sagrado.

Este projeto é consequência de uma pesquisa que ocorreu entre 2006 a 2008 denominada Espaço Sagrado nas águas do Paraná, financiada pelo SESI/Paraná, que mapeou os espaços religiosos no território Paranaense, produzindo uma coleção de fotografias sobre estes espaços e o livro publicado pela Editora Intersaberes O Sagrado: fundamentos e conteúdo do ensino religioso de 2008. Uma segunda fase da pesquisa foi desenvolvida no período de 2012 a 2014 sobre os espaços na cidade de Curitiba que finalizou com a elaboração de um vídeo em $360^{\circ}$ para formação de professores; e, a última fase, entre 2015 a 2016, quando foi articulado o trabalho sobre os Templos para elaboração metodológica do ensino religioso.

Estas três fases favoreceram articulação dos fundamentos e o estabelecimento de referências para aplicabilidade do espaço sagrado como mediação de aprendizagem. Nesse sentido, a presente pesquisa pretende apresentar e analisar três experiências do uso do espaço religioso com a atividade de educação patrimonial realizadas em Curitiba por meio de um estudo de caso qualitativo. Essa análise é feita por meio de entrevistas realizadas com os profissionais responsáveis pela atividade de mediação cultural nesses espaços com a finalidade de compreender a importância da mediação no patrimônio cultural para a educação cultural e religiosa dos participantes.

Para aprofundar o conhecimento sobre as atividades de educação patrimonial voltadas para o sagrado na cidade foi realizado um levantamento de informações sobre ações culturais em espaços que remetem a conteúdos religiosos e, posteriormente, escolhido os de maior relevância e que apresentaram regularidade de visitas para a construção do estudo. O enfoque de cada um também contou para a escolha final, uma vez que são atividades em locais diferentes, com dinâmicas distintas de abordagem. Assim, foram escolhidos o roteiro $\mathrm{Na}$ Trilha do Sagrado, a Visita guiada na Catedral Basílica 
Menor Nossa Senhora da Luz e a Visita noturna ao Cemitério Municipal de Curitiba. Definidas as atividades, entrou-se em contato com os respectivos profissionais para aplicar um questionário de doze questões de modo a conhecer melhor a ação cultural e a sua relevância para a educação patrimonial religiosa dos participantes.

\section{CONTEXTO DA CIDADE}

Inicialmente é fundamental compreender o espaço deste processo que é a cidade de Curitiba que, a partir dos anos 40, organizou o primeiro de muitos planos diretores que iriam mudar o seu futuro. A gestão dos governos de Curitiba efetivamente investiram em sua urbanização, sem deixar de lado os elementos naturais para melhor atender seus habitantes e passou a trabalhar com uma atividade até então não explorada: o turismo. A cidade ganhou muitos parques, um bom sistema de transporte público, investiu na reciclagem de lixo tornando-se referência mundial e, também, procurou investir em cultura para sua população.

A cidade passa a ser conhecida como uma das cidades no mundo que preserva o meio ambiente ou que oferece uma melhor qualidade de vida para seus habitantes. Curitiba transmite uma visão de cidade que dá valor às manifestações culturais, sendo que possui um dos melhores festivais de teatros do país, além de museus e centros culturais para todos os gostos. Com isso, vem crescendo o interesse por atividades que contemplem visitas mediadas nos inúmeros espaços culturais da cidade, com a finalidade de fornecer informações sobre a história e desenvolvimento de Curitiba, acrescentando novos conhecimentos para os participantes.

Fundada no dia 29 de março de 1693, pelas mãos do Capitão-Povoador Matheus Leme, foi primeiramente a Vila de Nossa Senhora da Luz e Bom Jesus dos Pinhais, posteriormente foi denominada de Curitiba. Seu nome é uma palavra de origem guarani: kur-yt-yba, na linguagem dos índios, quer dizer "grande quantidade de pinheiros, pinheiral”. Os primeiros habitantes do território a chamaram por esse nome, kur-yt-yba, devido à grande quantidade de Araucária angustifólia, o pinheiro-do-Paraná.

A princípio, no período colonial, foi povoada por índios, portugueses, espanhóis e africanos. Depois vieram os imigrantes europeus, principalmente, alemães, poloneses e italianos e, em menor número, ucranianos, franceses e ingleses. Mais tarde, os japoneses e sírio-libaneses juntaram-se à cidade, efetivamente a mistura de diversas etnias, 
principalmente europeias, Curitiba acabou ganhando um traço único e costumes diferenciados das demais cidades brasileiras. De fato a cidade cresceu e sua população também. Então surgiu a necessidade de se criar um ordenamento territorial que facilitasse esse crescimento de maneira adequada.

Por isso, foi implantado em Curitiba um dos primeiros planos diretores do Brasil, o Plano Agache. Além de um sistema de vias, o plano propunha um ordenamento espacial da cidade, onde ela passa a ser dividida por setores como administrativo, residencial, militar, entre outros. Também, pretendia melhorar o saneamento, o abastecimento de água e criar mais espaços de áreas verdes na cidade (FENIANOS; SADE, 1996).

Porém, o crescimento acelerado da cidade, no final dos anos 50, faz aparecer novos problemas e tornam o Plano Agache defasado. A partir da década de 60, surgem outros planos diretores que objetivaram reverter os congestionamentos das áreas centrais da cidade. Em 1965, foi desenvolvido o APPUC (Assessoria de Planejamento e Pesquisa Urbana de Curitiba), que mais tarde viria a se tornar um instituto e cujos objetivos eram elaborar projetos e encontrar soluções para os problemas urbanísticos da cidade.

Na década de 70 e 80, foi criado e desenvolvido o Plano Diretor de Urbanismo. Foi através deste plano que o planejamento de Curitiba incluiu a parte ambiental como objeto de importância e, por conseqüência, o urbanismo da cidade torna-se ecológico. Com o seu atual prefeito, Jaime Lerner, o plano diretor atingiu, além da estrutura física (principalmente no que se refere ao transporte coletivo), a área ambiental com a implantação de vários parques, a área cultural com a revitalização do patrimônio de Curitiba e também a área econômica e social com a criação da Cidade Industrial e de núcleos regionais voltados à comunidade.

$\mathrm{Na}$ década de 90, finalmente, Curitiba ganha o título de Capital Ecológica. De acordo com o site do Instituto de Pesquisa e Planejamento Urbano de Curitiba, o IPPUC (2017), na cidade "são criados seis novos parques, o Jardim Botânico e oito bosques, que somados totalizam mais de oito milhões de $\mathrm{m}^{2}$ de áreas verdes públicas”.

Além disso, surgem os ligeirinhos e os biarticulados para facilitar o transporte de um número maior de passageiros; as "Ruas da Cidadania", para assistência social e os “Faróis do Saber”, que são bibliotecas disponíveis, não só para alunos, como também para os demais cidadãos.

Por fim, Curitiba se preparou para o futuro, investindo na preservação da sua identidade cultural, criando memoriais e parques que homenageiam cada etnia que aqui 
reside, como o Bosque do Papa, Bosque do Alemão, Praça do Japão, Memorial Ucraniano e também, homenageando ela mesma, em sua comemoração de 300 anos de vida, criando o Memorial da Cidade. Agora, passado a fama de capital ecológica, Curitiba se preocupa em passar a imagem de cidade que se preocupa em melhorar a qualidade de vida de seus habitantes.

Está entre as cinco melhores cidades para se investir na América Latina. Isso se deve a boa localização da cidade, perto de São Paulo e também do Porto de Paranaguá e também graças à sua infra-estrutura e à sua região metropolitana que atraiu grandes empresas como Siemens, Kraft e HSBC. Curitiba também é um dos maiores pólos automotivos do país com montadoras de destaque como Volks-Audi, Renault, Volvo e Nissan.

Como a cidade é extremamente urbanizada, Curitiba não contribui tanto com a agropecuária, mas sim com a indústria e serviços, principalmente nos gêneros alimentícios, farmacêuticos e metalúrgicos. Além disso, conta com o Aeroporto Internacional Afonso Pena que facilitam os negócios na cidade.

Curitiba sempre foi referencial quando o assunto é preservação ambiental e, de acordo com o site da Prefeitura Municipal (CURITIBA, 2017), a cidade "[...] tem um dos melhores índices de áreas verdes do País: 52 metros quadrados por habitante, totalizando aproximadamente 82 milhões de $\mathrm{m}^{2}$.” Essa preocupação com o meio ambiente refletiu na constante preocupação com a reciclagem de lixo e na criação de inúmeros parques disponíveis para a população que a cidade oferece.

A "rede integrada de transportes" também foi uma tentativa de priorizar o transporte coletivo para evitar tanto a poluição dos veículos particulares. Trata-se de um sistema de transportes com via exclusiva para ônibus biarticulados e interligação com terminais onde os passageiros podem completar sua viagem fazendo transferência de ônibus sem pagar outra passagem. Porém, o crescimento da cidade não comportou esse sistema e, hoje, já se comenta a possibilidade de construção de um metrô.

Apesar de Curitiba ser uma das melhores cidades do Brasil quando o assunto é Turismo de Negócios, ela também vem investindo em outro público, que é o turista que busca lazer e entretenimento. Hoje, a cidade vem tentando se manter também como um destino cultural, afinal tem mais de 300 anos e portanto seu patrimônio é rico e diversificado. 


\section{PRIMEIRA EXPERIÊNCIA}

A experiência inicial selecionada é a Trilha do Sagrado: Redescobrindo o Centro Histórico de Curitiba que foi desenvolvida pela Secretaria Municipal da Educação para apresentar a diversidade religiosa de Curitiba, sem sair do centro da cidade. Durante o passeio, que tem duração aproximada de duas horas e feito a pé, os participantes conhecem a cultura, fé e a história das quatro matrizes religiosas: cristã, oriental, africana e indígena.

A trilha começa na Praça Tiradentes, onde os participantes conhecem os irokos (árvores dispostas em círculos e que são sagrados para as religiões de matriz africana), a escultura do índio Tindiquera e a Catedral de Curitiba, seguindo pelo Largo da Ordem, onde conhecem as Igrejas da Ordem, Presbiteriana, Independente e do Rosário, pela sede do instituto Hare Krishna, pela Igreja Luterana e pela mesquita Iman Ali Ibn Abi Talib. Em cada local, é apresentado os aspectos religiosos do local, a arquitetura, história, origem, entre outras informações e também é tirado as dúvidas dos participantes.

Em entrevista realizada com a responsável pela Trilha, a professora Karin Willms $(2007)^{1}$, buscou-se maiores informações a respeito da concepção, objetivos e diferenciais da atividade.

\section{FIGURA 1 - Visita na Mesquita de Curitiba}

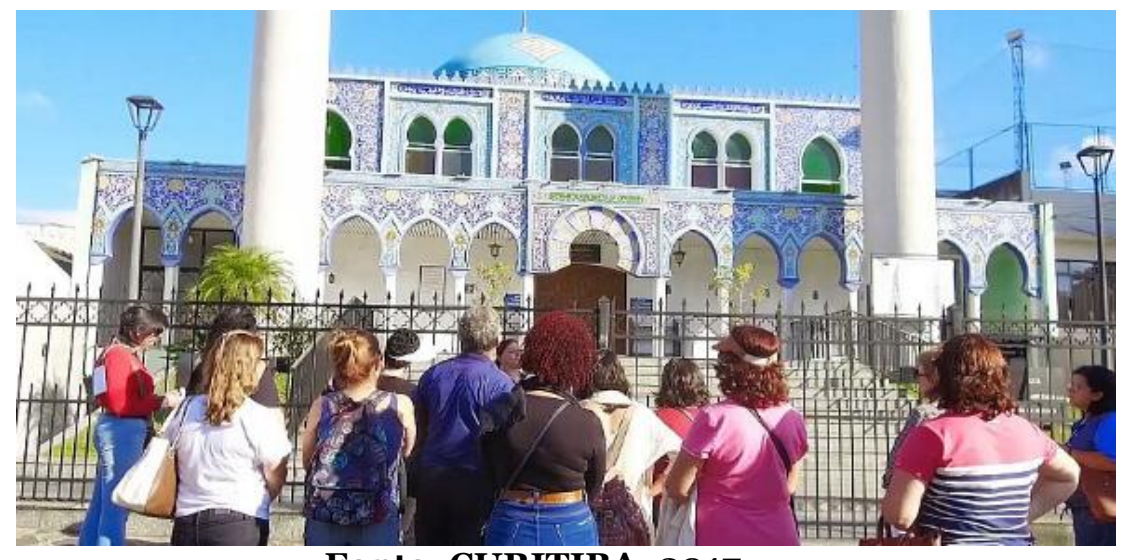

Fonte: CURITIBA, 2017

Segundo Willms (2017), a ideia da criação da Trilha surgiu quando foi pedido um encaminhamento de uma atividade de cada disciplina para trabalhar o aniversário de Curitiba. Então, olhando para o currículo do primeiro semestre do ensino religioso que

\footnotetext{
${ }^{1}$ Entrevista com a professora da rede municipal de ensino e integrante da equipe de currículo da Secretaria da Educação.
} 
aborda os lugares sagrados e organizações religiosas, foi desenvolvido para as crianças pequenas um jogo de memória com alguns lugares sagrados das quatro matrizes religiosas e para os mais velhos foi distribuído um mapa do site da prefeitura com os lugares sagrados do Largo da Ordem marcados, onde a criança percorria esse mapa e, cada vez que encontrava um lugar sagrado, ganhava uma cartinha contendo alguma informação dele.

Quando esse material chegou na escola para os professores, alguns falaram assim "nossa, isso fica no centro? Eu nunca vi” E aí surgiu a ideia de pegar então esse grupo de professores de ensino religioso e fazer essa visita por esses lugares que faziam parte desse jogo. E foi assim que surgiu o projeto. Aí a prefeitura fez todo o acompanhamento junto com a gente, no dia que a gente fez a Trilha eles fizeram a filmagem e colocaram no facebook e aí a gente começou a receber ligação da população "olha, tem como a gente participar também?”, “vai ter de novo?”, e aí a gente abriu agora, sábado, a gente terá a segunda turma aberta a comunidade, vamos ter com as crianças, já vai fazer parte da semana cultural em setembro, então foi assim uma coisa inesperada mesmo a repercussão que teve. (WILLMS, 2017). ${ }^{2}$

Com relação as motivações que levaram a realização da atividade, Willms (2017) conta que no dia de aniversário de Curitiba houve uma aula magna do prefeito sobre a história da cidade para as crianças dentro da Catedral o que acabou causando um mal estar por passar a impressão que estando o prefeito ao lado da Igreja Católica seria isso que haveria de ser trabalhado no ensino religioso dali em diante. Assim, com a realização da Trilha, essa impressão foi desmistificada para provar que a Secretaria Municipal da Educação está lutando para que as pessoas entendam a diversidade religiosa e que o ensino religioso está ao lado da diversidade de manifestações religiosas contidas em nossa sociedade e não somente da Igreja Católica.

Assim, o principal objetivo da atividade é mostrar para as pessoas que Curitiba possui uma grande diversidade religiosa o que causa muita surpresa nos participantes, por exemplo, quando é contado que a cidade tem o segundo maior terreiro de Umbanda no Brasil.

Se falar em Umbanda e Candomblé as pessoas falam "ah, é na Bahia” e o segundo maior tá aqui, ou "Como assim te uma aldeia urbana em Curitiba?", ou "Como assim tem muçulmanos em Curitiba?”, então o objetivo principal é mostrar que essas religiões existem, estão presentes em Curitiba e convivem ali num espaço de mil e duzentos metros, nós temos mais de dez lugares sagrados e várias organizações diferentes convivendo juntas e harmoniosamente, sem ninguém precisar brigar com ninguém. (WILLMS, 2017). ${ }^{3}$

\footnotetext{
2 Entrevista com a professora Karin Willms.

3 Entrevista com a professora Karin Willms.
} 
Com relação ao número de participantes de cada encontro, segundo Willms (2017) com os grupos de professores, no primeiro grupo foram 40 professores e no segundo 60 professores; com a comunidade no primeiro foram 50 inscritos e para sábado próximo, 70 inscritos. Já com as crianças será um grupo de apenas 30. "Com as crianças temos que fazer um grupo reduzido, pois como eles são muito pequenos o tempo de concentração é muito pouco, eles se distraem muito facilmente, então não dá para fazer com um grupo grande." (WILLMS, 2017). 4

O projeto das visitas começou em abril de 2017 e a Trilha está atualmente (durante a elaboração do presente artigo) no quinto encontro, e, portanto, a regularidade da Trilha depende da procura que até o momento está sendo grande.

Com relação à expansão da atividade, ideias a gente tem muitas, existe um roteiro religioso em Curitiba, a Secretaria de Turismo tem um folder com vários (três) diferentes, lógico que isso demandaria uma questão financeira muito grande, se houver a possibilidade quem sabe um dia a gente possa fazer de ônibus esse roteiro completo. A ideia existe, agora entra a questão financeira e a gente precisa da Secretaria de Transportes, Secretaria de Turismo, aí a gente precisa fazer um trabalho maior. (WILLMS, 2017). 5

Quanto ao perfil dos participantes, as duas primeiras visitas foram de professores do ensino religioso. Com a comunidade, houve adesão de professores de história do estado, estudantes de história, a dona de uma joalheria, crianças de dez anos de idade até senhoras de setenta anos, ou seja, um público bem eclético. "Nós tivemos uma procura muito grande de guias de turismo, nós temos para sábado agora uma dentista inscrita, um segurança do SESI, então é uma diversidade muito grande." (WILLMS, 2017). ${ }^{6}$

Inclusive a Trilha foi convidada a fazer parte da semana cultural em Setembro, na qual os professores, no dia da permanência, recebem uma lista de eventos culturais que podem participar. Segundo Willms (2017), existe a possibilidade de criar dentro do Setor de Cultura da Educação um núcleo de Cultura Religiosa o que auxiliaria em muito na divulgação da Trilha, "porque a gente faz a divulgação no Ensino Religioso, mas atinge um público muito pequeno, se a gente consegue essa parceria da parte da Cultura a gente atinge toda a rede e são dezessete mil professores enquanto que, de ensino religioso, são apenas trezentos."7

\footnotetext{
4 Entrevista com a professora Karin Willms.

5 Entrevista com a professora Karin Willms.

6 Entrevista com a professora Karin Willms.

7 Entrevista com a professora Karin Willms.
} 
Alguns aspectos significativos da Trilha, como conta Willms (2017), é que durante o trajeto, é possível perceber como a educação em história e geografia dos participantes é falha, pois quem tem mais de vinte anos não tem tanto conhecimento de outras etnias que não a européia em Curitiba.

E mesmo aspectos que a gente estuda na escola, eu percebi assim com os professores a curiosidade que surgiu quando a gente chegou na Igreja Luterana, eu sou historiadora, o Luteranismo para mim estava mais do que batido já porque a gente estuda na escola, a gente fica seis meses do ensino médio trabalhando só isso. Então a gente percebe o desconhecimento do espaço. Então a gente consegue através desse trabalho detectar algumas falhas no processo formador, a própria questão do indígena Tindiquera, o Cacique, que agora a estátua está ali na frente da Catedral, pra mim que estudei na escola da prefeitura, estava mais do que óbvio que todo mundo sabia quem ele era. E as pessoas não sabem. Então eu acho muito significativo perceber como as pessoas desconhecem a sua própria história e poder contribuir para que conheçam um pouquinho e que tenham a curiosidade de pesquisar mais sobre. (WILLMS, 2017). ${ }^{8}$

Outra questão apontada por Willms (2017) é que a Trilha valoriza o trabalho do professor de Ensino Religioso, pois além de mudar a visão da própria disciplina, o roteiro motiva os professores em seu trabalho diário, “porque professor de Ensino Religioso é muito marginalizado dentro da própria escola, desde a escolha da função até o trabalho que ele desenvolve, ele sofre muito preconceito dentro da própria escola”. Com a divulgação da Trilha, no site da prefeitura, no facebook, com as entrevistas dadas em rádios da cidade, torna visível a importância do trabalho do professor de Ensino Religioso para a sociedade.

A gente vê que as professoras estão mais motivadas em sala de aula, porque as pessoas questionam 'você é professora de Ensino Religioso? Então você faz aquilo que está no facebook? Poxa, que legal o trabalho que você faz'. Então acho que isso foi um movimento muito legal que surgiu a partir do projeto. (WILLMS, 2017). ${ }^{9}$

Com relação à compreensão do cenário religioso por parte dos participantes, Willms (2017) destaca exemplos como a lavação das escadarias da Igreja do Rosário, evento que fica muito fechado no grupo religioso e com a visita é possível falar desses eventos para as pessoas que não fazem parte daquela organização ampliando assim o conhecimento. Outro exemplo são os irokos, que, quando explicado a história do porquê aquelas árvores são sagradas, as pessoas conseguem entender melhor a manifestação religiosa de matriz africana e quando estiverem andando pela cidade e encontrarem uma oferenda embaixo,

${ }^{8}$ Entrevista com a professora Karin Willms.

9 Entrevista com a professora Karin Willms. 
estiver com flores, a visão já vai ser bem diferente relacionada aquele lugar, a questão do respeito de entender que aquela árvore naquele momento é um lugar sagrado para uma determinada pessoa e deve ser respeitado.

Eu acho que conversar sobre a origem, sobre a sacralidade desses lugares, ele amplia sim a visão do que é sagrado para o outro, do que é sagrado para mim, até você compreender mesmo o que quer dizer sagrado, porque até então sagrado é a Igreja e ponto, e a partir dessa visita eles conseguem entender que uma árvore, uma flor, uma fonte de água também configuram um lugar sagrado dependendo de quem está observando aquele espaço. (WILLMS, 2017). ${ }^{10}$

Outra questão perguntada a Willms (2017) é em que medida a visita agrega conhecimentos históricos, culturais e religiosos aos participantes. A professora responde que em cada local do roteiro, existe uma ficha base contendo diversas informações sobre os locais como o ano de fundação, qual a organização religiosa que trouxe esse espaço para cá, por que o local foi escolhido, de qual lugar do mundo vem aquela organização, aonde ela surgiu, quando veio para cá, como que se dá a organização das pessoas ali dentro daquele espaço, quando que aquele espaço foi determinado como sagrado, constituindo-se de vários aspectos históricos e culturais transmitidos durante a visita. Por exemplo,

[...] por que o sino da Igreja Luterana só foi colocado naquela data? Porque naquela data a constituição federal passou a determinar a liberdade religiosa, então a partir do momento que é reconhecida pela Constituição Federal se coloca o sino na Igreja, ela não precisa mais se esconder. (WILLMS, 2017). ${ }^{11}$

Com relação aos locais que chamam mais a atenção dos participantes, Willms (2017) conta que são diferentes tipos de reações, porém o que chama mais a atenção é, sem dúvida, o Hare Krishna, porque a religião de matriz africana tem a questão da resistência, tem aquele preconceito, então chama a atenção, choca, mais a própria mídia vem trazendo informações com frequência, tem a questão da legislação ético-racial, mas quando as pessoas chegam no Hare Krishna, porque são pessoas que eles sempre veem na rua, ali no Largo da Ordem vendendo livro, durante a feirinha passeando, é uma coisa que gera uma curiosidade muito grande. "E quando você conta que as pessoas moram no templo, costumam questionar: 'mas, espera aí: é um lugar sagrado, é um templo, mas é a casa deles?', então, ali eu acho que é um lugar que chama muito a atenção.” (WILLMS, 2017). ${ }^{12}$

10 Entrevista com a professora Karin Willms.

11 Entrevista com a professora Karin Willms.

12 Entrevista com a professora Karin Willms. 
Foi questionado também se a professora gostaria que algo fosse alterado na atividade. Willms (2017) nos conta que gostaria que todos os espaços ficassem abertos poder entrar, porque eles conseguem entrar na Catedral, que está sempre aberta, na Igreja da Ordem, que até tem o museu de Arte Sacra e é possível visitar, porém já a Luterana só abre terça, quarta e quinta, a Presbiteriana sempre está fechada, o Hare Krishna até pode entrar, mas se entrar acabam ficando umas quatro horas lá dentro, porque daí os representantes da religião querem falar, pois são muito acolhedores. "Então se esses espaços abrissem a porta para a gente poder entrar sem a interferência do líder, entrar, ver e sair, eu acho que seria um ganho muito grande. Mas a gente não conseguiu ainda essa abertura”.

Para finalizar a entrevista, a professora foi questionada a respeito dos benefícios da educação patrimonial para nossa sociedade. Willms (2017) acredita que a importância da educação patrimonial é que a pessoa desenvolva sua própria identidade com o local do qual ela faz parte.

Eu por exemplo, nasci, cresci em Curitiba, estudei a vida toda, mas hoje eu moro na região metropolitana. Uma coisa que eu percebo com os adolescentes da religião metropolitana é que eles não tem identidade local, porque eles estudam em Curitiba, eles trabalham em Curitiba, eles vão ao shopping em Curitiba, eles vão ao parque em Curitiba, só que eles não são curitibanos. Então eles não tem identidade local. Eu acho que a educação patrimonial, quando você pega as crianças ou os adultos mesmo que são daquela localidade e eles começam a conhecer os lugares, os elementos que constituem a cultura da sua cidade, eles desenvolvem uma identidade local, um pertencimento da sua cidade. (WILLMS, 2017). ${ }^{13}$

Outro exemplo que a professora coloca é a árvore Araucária, patrimônio de Curitiba, que transforma-se em elemento identitário mesmo quando o indivíduo está longe de seu local de origem. Assim, onde ele visualiza uma araucária, independente de estar em outro lugar, ele sente o sentimento de pertencimento. "A criancinha que é de matriz africana, quando ele chega ali na Tiradentes e a professora fala 'olha, essa árvore é sagrada da religião do Joãozinho', então é o meu lugar, eu estou no meu espaço. Essa questão de pertencimento ao local de origem ou de moradia.” (WILLMS, 2017). ${ }^{14}$

13 Entrevista com a professora Karin Willms.

14 Entrevista com a professora Karin Willms. 


\section{SEGUNDA EXPERIÊNCIA}

Uma segunda ação é a Visita guiada na Catedral Basílica Menor Nossa Senhora da Luz que está localizada no marco zero de Curitiba, na Praça Tiradentes, e é considerada um patrimônio cultural da cidade. A catedral foi construída em estilo neogótico - ou gótico romano - inspirada na Catedral da Sé de Barcelona, na Espanha. A visita tem duração de duas horas e foca nos aspectos históricos e arquitetônicos da Catedral. Em entrevista realizada com o responsável pela visita, o arquivista Gabriel Forgati (Arquivista da Catedral de Curitiba), buscou-se maiores informações a respeito da concepção, objetivos e diferenciais da visita.

\section{FIGURA 2 - Visita na Catedral de Curitiba}

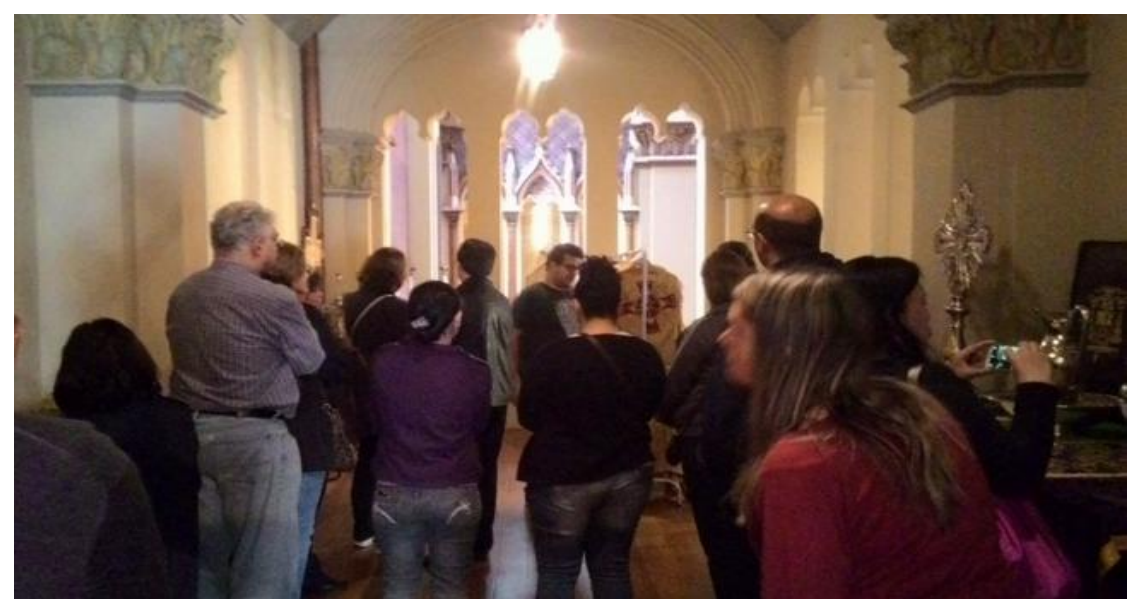

Fonte: (FORGATI, 2016) ${ }^{15}$

Forgati conta que a iniciativa de realizar a atividade partiu dele mesmo tendo em vista outros roteiros guiados já realizados na cidade, como a Visita Guiada ao Cemitério Municipal São Francisco de Paula e o Roteiro da presença da Escravidão em Curitiba, conhecido como Linha Preta. ${ }^{16}$

Com relação às motivações que o levaram a desenvolver a atividade, Forgati (2017) afirma que a Catedral Basílica é de imensurável importância não apenas religiosa, mas também histórica, social, artística e arquitetônica e, por isso, é importante que haja seu reconhecimento.

\footnotetext{
15 Entrevista realizada, no dia 10 de setembro de 2017, com o arquivista Gabriel Forgati, responsável pela visita guiada na Catedral de Curitiba.

16 Entrevista com o arquivista Gabriel Forgati.
} 
Como a iconografia/arquitetura religiosa é sempre eloquente em simbologia, principalmente, bíblica teológica e litúrgica, esse reconhecimento parte de compreender toda e cada uma das representações existentes no interior e no exterior da Igreja Catedral Basílica. (FORGATI, 2017). ${ }^{17}$

O principal objetivo da visita é difundir a iconografia/arquitetura religiosa e seus diversos elementos bem como a história do atual templo e da Paróquia Nossa Senhora da Luz dos Pinhais, que remonta à segunda metade do século XVII, e que por sua vez mesclase com a história da própria Curitiba. Objetiva-se também expor a Catedral Basílica como um espaço de sociabilidades e convivência da sociedade curitibana nos variados estamentos e situar a igreja como um marco na cidade, sob todos os aspectos.

Com relação ao número de participantes de cada encontro, segundo Forgati, é aberto uma listagem para em geral 50 participantes por visita sendo que o maior público foi de 62 pessoas e o menor de 21. Já com relação à regularidade de visitação, os encontros são realizados uma vez por mês, quase sempre aos sábados pela manhã, das 9h às 11h30. Demandas específicas por enquanto ainda não são atendidas.

Quando questionado a respeito do perfil dos visitantes, Forgati afirma ser extremamente variados, desde famílias inteiras, jovens, idosos, casais, mesmos ativos de comunidades paroquiais em Curitiba, turistas, até estudantes de diversas áreas (sobretudo História, Arquitetura e Turismo) e guias de turismo.

Segundo Forgati (2017), os aspectos mais significativos desta atividade são o de desmistificar sensos comuns enraizados há tempos; o interesse demonstrado pelos próprios participantes; e também ser a primeira atividade dessa natureza empreendida com afinco na Catedral.

Com relação à compreensão do cenário religioso durante o encontro por parte dos participantes, Forgati (2017) afirma que eles conseguem compreender com clareza, pois:

[...] durante a visita são feitas diversas exposições acerca de normativas litúrgicas e teológicas, para que os participantes possam entender os motivos de tal mobiliário/imagem/ornamento/pintura etc estar situado de certa maneira ou configurarse de uma determinada forma, e não de outras. Como as rubricas eclesiásticas eram, à época da construção do atual templo (1876-1893), extremamente rígidas, é possível estabelecer paralelos e precedentes. (FORGATI, 2017). ${ }^{18}$

17 Entrevista com o arquivista Gabriel Forgati.

18 Entrevista com o arquivista Gabriel Forgati. 
Forgati (2017) acredita que a visita agrega conhecimentos históricos, culturais e religiosos aos participantes na medida em que aglutina todas essas categorias. "Como herança do passado colonial português, o imaginário católico perpassa a sociedade de forma profunda, e como a história acaba por estudar a sociedade e suas expressões, a religiosidade católica toma grande parte desse espectro.” (FORGATI, 2017). ${ }^{19}$

Quando questionado sobre qual obra, monumento, espaço, chama mais a atenção dos participantes, Forgati (2017) acredita que, sem dúvidas, o que chama mais a atenção durante a visita é o Órgão de Tubos, quando os participantes vão até o coro para vê-lo de perto.

Além disso, durante a entrevista, questionou-se a respeito de possíveis alterações para a visita que o arquivista achava relevante com o intuito de aumentar a demanda. Forgati (2017) acredita que deveriam ser alterados os métodos de divulgação, como ele conta a seguir.

Hoje, conto apenas com o meu perfil do Facebook para divulgação das visitas, geralmente duas semanas antes, e a publicação acaba compartilhada pela Página da igreja Catedral Basílica, da Arquidiocese de Curitiba, do Guia de Visitação ao Cemitério Municipal São Francisco de Paula, e por pessoas interessadas e ainda por aqueles que já participaram das mediações. (FORGATI, 2017). ${ }^{20}$

Para finalizar a entrevista, questionou-se a opinião do arquivista com relação aos benefícios da educação patrimonial para nossa sociedade. Forgati (2017) acredita que a educação patrimonial corrobora para a manutenção do patrimônio. Nesse sentido, "resgatar a história de um patrimônio histórico incita curiosidade e interesse sobre ele próprio, e atribuir seus usos do passado de forma próxima à sociedade atual facilita sua manutenção, pois cria disposição na sua conservação, tanto da população quanto dos órgãos públicos.”(FORGATI, 2017). ${ }^{21}$

\section{TERCEIRA EXPERIÊNCIA}

A terceira ação é a visita noturna guiada no Cemitério Municipal de Curitiba. O Cemitério São Francisco de Paula, importante patrimônio histórico da cidade foi inaugurado em 1854 pelo presidente de província Zacarias de Góes e Vasconcellos e abriga,

19 Entrevista com o arquivista Gabriel Forgati.

20 Entrevista com o arquivista Gabriel Forgati.

21 Entrevista com o arquivista Gabriel Forgati. 
em mais de 5 mil túmulos, grande parte das personalidades responsáveis pela história da cidade de Curitiba e do estado do Paraná (CURITIBA, 2017).

Em entrevista realizada com a responsável pela visita, a pesquisadora Clarissa Grassi $^{22}$ revela detalhes sobre a visita, um pouco da história e dos benefícios da atividade para a cidade de Curitiba.

\section{FIGURA 3 - Visita ao Cemitério Municipal de Curitiba}

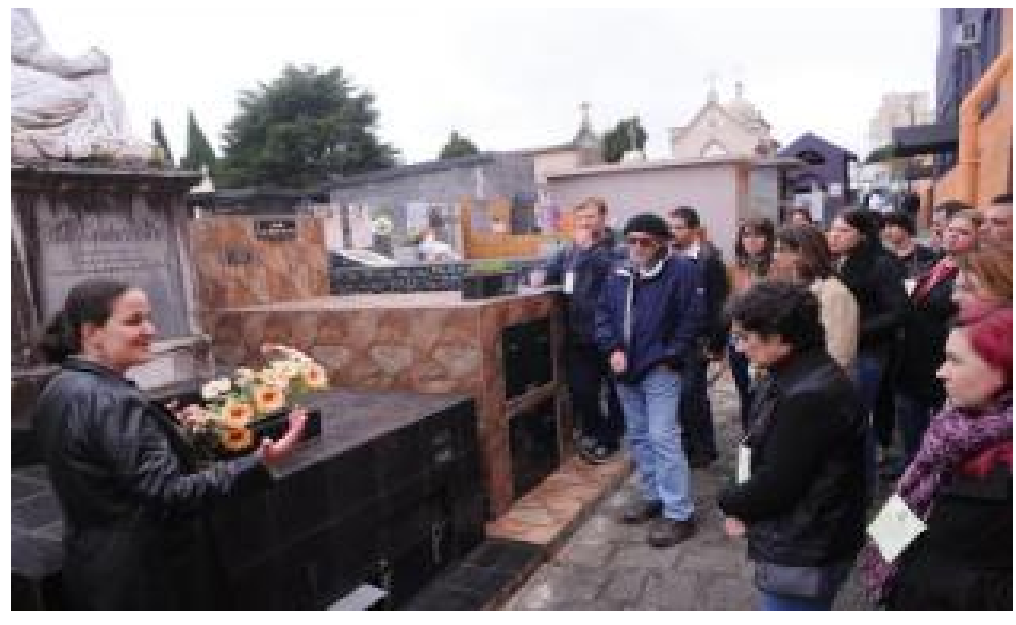

Fonte: Curitiba, 2017

Grassi (2017) conta que a iniciativa de começar a atividade partiu dela mesma com o objetivo de divulgar as pesquisas que já realizava no espaço desde 2003. Nesse sentido, a visita seria uma forma de mostrar o passado de Curitiba partindo do cemitério como ponto de destinação final de diversas personalidades.

Em 2006, quando lancei o livro 'Um olhar... A arte no silêncio' realizei uma visita guiada com os mediadores da Fundação Cultural de Curitiba para que conhecessem in loco as esculturas retratadas na exposição fotográfica conjunta com o lançamento do livro. Ao expandir as pesquisas, vi no cemitério um grande aglutinador da história de Curitiba, mas esquecido e relegado ao tabu da morte. (GRASSI, 2017). ${ }^{23}$

Com relação às motivações que levaram a realização da atividade, Grassi (2017) aponta que foi a forma que encontrou de popularizar a pesquisa e atrair a população sob um viés diferenciado, uma maneira de cativar o olhar dos participantes tirando a morte do centro da questão e colocando outros aspectos como arquitetura, arte, geologia, história e simbologia como elementos norteadores do passeio.

\footnotetext{
22 Entrevista com a Clarissa Grassi, pesquisadora da Fundação Cultural de Curitiba e Presidente da Associação Brasileira de Estudos Cemiteriais

23 Entrevista com a pesquisadora Clarissa Grassi.
} 
No período de concepção do roteiro, Grassi estava preparando o "Guia de Visitação ao Cemitério Municipal São Francisco de Paula - arte e memória no espaço urbano" composto por um livro (lançado em 2014) e que traz a biografia e a descrição dos túmulos sob o olhar da arquitetura, geologia, história e sociologia. "São 99 personalidades abordadas em 10 trajetos temáticos de visitação como Arquitetura, Arte tumular, Geologia, Músicos, Intelectuais, Artistas, Empresários, Políticos, Personalidades e Ritos e Fé." (GRASSI, 2017). ${ }^{24}$ Assim, a visita seria uma forma de compartilhar gratuitamente todo esse conteúdo e de sensibilizar as pessoas sobre sua importância.

Segundo Grassi (2017), o objetivo pretendido com a realização da visita é desmistificar o cemitério como apenas um repositório de corpos, demonstrando todo seu potencial como resumo simbólico da sociedade na qual está inserido, nesse caso a cidade de Curitiba. Também se busca trazer a tona o cemitério como fonte de pesquisa de questões como imigração, ciclos econômicos, geodiversidade, modismos, arquitetura, secularização do estado, aspectos religiosos, mas acima de tudo, sua capacidade enquanto patrimônio edificado. Ou seja, durante a visita é possível repassar aos visitantes um pouco da história da cidade e do estado a partir dessas construções e de seus ocupantes, procurando gerar o sentimento de pertença, apresentando-o como um bem a ser preservado e conhecido. "Outra questão é a de municiar os participantes com informações que os possibilitem realizar suas próprias leituras quando da visitação de outros cemitérios. Ou seja, calibrar seus olhares para entender o processo de construção das necrópoles e suas singularidades." (GRASSI, 2017). ${ }^{25}$

Com relação ao número de participantes, a pesquisadora afirma que as turmas possuem em média de 30 a 40 pessoas, pois há uma limitação de até 40 participantes em função da disponibilidade espacial do cemitério, que possui muitas ruas estreitas, o que dificulta a interação e visualização das obras e túmulos. Fazendo um levantamento de todos os roteiros realizados, Grassi (2017) aponta que entre 2011 e 2016 foram atendidos mais de 3.300 participantes. Já com relação ao número de visitas realizadas a pesquisadora afirma que "desde 2014 as visitas são realizadas mensalmente e a partir de 2017 passaram a ocorrer duas vezes ao mês, sendo uma visita padrão e outra temática, ligada a uma data comemorativa do mês corrente. Existem ainda as visitas noturnas que

24 Entrevista com a pesquisadora Clarissa Grassi.

25 Entrevista com a pesquisadora Clarissa Grassi. 
são feitas esporadicamente, geralmente em três noites seguidas.” (GRASSI, 2017). ${ }^{26}$

O perfil das pessoas que se inscrevem para participar da atividade não é específico, segundo Grassi (2017): "Recebemos pessoas das mais variadas classes sociais, faixas etárias e escolaridade. Crianças, idosos, adolescentes... Já tive participante de 87 anos, assim como bebês de colo ou um menino de três anos que veio participar com os pais de uma visita noturna”. ${ }^{27}$ Um fato importante apontado pela pesquisadora é que alguns participantes que fazem o roteiro costumam retornar em outras edições da visita e também trazem outros participantes, geralmente familiares e amigos. "Quando questionados, respondem que o conteúdo é vasto, não pode ser apreendido em apenas uma visita." (GRASSI, 2017). E também existem aqueles que fazem uma visita temática ou noturna e que retornam para acompanhar a visita padrão e vice-versa, uma vez que existem roteiros diferentes ofertados no cemitério.

Quando questionada sobre o fato de o espaço auxiliar os participantes a compreender o cenário religioso, Grassi (2017) afirma que "a intenção não é enfocar o cenário religioso, mas a relação do homem com a morte ao longo do tempo, demonstrando momentos de aproximação e afastamento. Não considero uma atividade de cunho religioso e sim de educação patrimonial”. (GRASSI, 2017). ${ }^{28}$ A pesquisadora acredita que ainda que o catolicismo possua um papel muito importante nesses espaços, já que o cemitério oitocentista é implantado antes da secularização do estado, a abordagem é feita de forma a mostrar influências ao longo do tempo, pontuando símbolos e significados. "Procuro demonstrar de forma empírica esse processo de afastamento e higienização da morte e seu reflexo nas construções dos túmulos e do uso cada vez mais racional do espaço.” (GRASSI, 2017). ${ }^{29}$

Quando questionada sobre em que medida a visita agrega conhecimentos históricos, culturais e religiosos aos participantes, Grassi (2017) afirma que os participantes acabam conhecendo literalmente ao pé do túmulo a trajetória de personalidades políticas, empresários, artistas, músicos, intelectuais entre outros, entendendo as tipologias tumulares e sua evolução ao longo do tempo, aspectos ligados a diferentes credos, assim como os modismos, materiais empregados nas construções, referências arquitetônicas.

\footnotetext{
26 Entrevista com a pesquisadora Clarissa Grassi.

27 Entrevista com a pesquisadora Clarissa Grassi.

28 Entrevista com a pesquisadora Clarissa Grassi.

29 Entrevista com a pesquisadora Clarissa Grassi.
} 
Trata-se de uma aula em campo, onde o contato com a história se dá de maneira direta. Tudo é demonstrado de forma concreta, seja na evolução das tipologias tumulares (cheias de símbolos religiosos no século XIX e extremamente racionais nos dias atuais), na visão mais racional da morte, como a semelhança com a cidade, cujas referências são constantemente elencadas ao ligarmos o nome da personalidade com a localização de sua casa, negócio ou feitos na cidade. (GRASSI, 2017). ${ }^{30}$

Com relação ao monumento, objeto ou obra que os participantes acham mais interessante, Grassi (2017) aponta serem os mausoléus que chamam mais a atenção geralmente pela monumentalidade e pela semelhança imagética com casas ou igrejas. Entretanto são vários túmulos com características particulares que em diferentes abordagens (arquitetônicas, artísticas ou geológicas) pontuam sua singularidade. "Um túmulo que sempre suscita discussão é o mausoléu da família Glasser, construído em forma de pirâmide com duas esculturas em sua entrada: uma esfinge e uma sacerdotisa. A grande maioria pensa que é uma obra única, que há ligação com a cultura egípcia." (GRASSI, 2017). ${ }^{31}$ Porém ao serem informados de que se trata da réplica de um túmulo construído na Itália, os participantes conseguem compreender o processo de disseminação da arte e arquitetura tumular em todo o mundo.

Quando questionada a respeito de possíveis alterações nos roteiros, a pesquisadora acredita que sendo a pessoa que organizou e implantou a atividade não se considera apta a sugerir alterações.

É um passeio longo, mas a maioria dos participantes é enfática ao afirmar que o tempo passa muito rápido e que a quantidade de informações é enorme. As avaliações que tenho recebido ao longo desses seis anos sempre foram extremamente positivas e a recidiva dos participantes em várias edições atesta a aceitação do formato. Com a implantação dos saraus de poesia, das visitas temáticas e noturnas, abrimos um leque de variações que se mostrou bem atrativo e que rapidamente se consolidou. (GRASSI, 2017). ${ }^{32}$

Para finalizar a entrevista, questionou-se a pesquisadora a respeito de sua opinião com relação aos benefícios da educação patrimonial para a sociedade. Grassi (2017) acredita que o patrimônio é memória, é ter uma referência sobre o passado sem perder o norte do presente e do futuro. É um ponto que podemos constantemente tomar como

30 Entrevista com a pesquisadora Clarissa Grassi.

31 Entrevista com a pesquisadora Clarissa Grassi.

32 Entrevista com a pesquisadora Clarissa Grassi. 
referência para entendermos de que forma nosso passado influenciou o presente.

Entretanto, patrimônio sem pertença não tem nenhum sentido. Sem ligação afetiva não há a busca pela preservação, pela valorização do espaço edificado, dos costumes, da cultura. É nesse contexto que a educação patrimonial tem um papel fundamental, o de fazer esse elo entre passado e presente, de apresentar o patrimônio suscitando a curiosidade, desmistificando visões e demonstrando de forma prática a importância que essa referência material ou imaterial tem para a sociedade da qual faz parte. Conhecer para ajudar a preservar.

\section{PATRIMÔNIO CULTURAL}

A noção de patrimônio teve início com a Revolução Francesa. Ele se inseriu no processo de consolidação dos Estados-nações modernos. Tinha a função de reforçar a noção de cidadania e instruir a nação. Além disso, era necessária a existência de um patrimônio conhecido para gerar uma identidade coletiva, para criar um sentimento de igualdade, de pertencer a uma determinada cultura. Nesse sentido, "O valor dos bens culturais, assim, tem a magnitude da consciência dos povos a respeito de sua própria vida." (SOUZA FILHO, 2005, p. 45). O passado que os bens culturais invocam não é um passado qualquer, "ele é localizado e selecionado para fins vitais, na medida em que pode, de forma direta, contribuir para manter e preservar a identidade de uma comunidade étnica ou religiosa, nacional, tribal ou familiar." (CHOAY, 2001, p. 18).

Etimologicamente falando, para Santana (2001, p. 170) "patrimônio significa bens herdados do país”. Para Barretto (2000, p. 9) a palavra patrimônio significa "conjunto de bens que uma pessoa ou uma entidade possuem”. O termo patrimônio é usado nas línguas românicas, vindo do latim patrimonium, algo que faça referência a uma herança adquirida dos pais ou dos antepassados. Já os alemães utilizam a palavra Denkmalplege, algo parecido com o cuidado daquilo que nos faz pensar. Portanto, as palavras possuem diversos significados, mas fazem a mesma referência, ou seja, lembrar, pensar, fazer uma ligação com o passado. Desta forma, para chegar a um consenso a "palavra patrimônio está historicamente associada ou à noção de sagrado, ou à noção de herança, de memória do indivíduo, de bens de família.” (BABELON; CHASTEL, 1994 apud SANTOS, 2001, p. 43).

Assim, o Patrimônio Cultural, que compreende todos os bens de natureza material e 
imaterial que façam referência à identidade e à memória de uma sociedade em particular, é, na atualidade, importante instrumento pedagógico, formal ou informal, para o exercício da cidadania. Nesse sentido, a educação em um ambiente não formal de ensino só é possível por meio da metodologia da educação patrimonial que é compreendida como "um processo permanente e sistemático de trabalho educacional centrado do patrimônio como fonte primária de conhecimento e enriquecimento individual e coletivo." (HORTA, GRUNBERG; MONTEIRO, 1999, p. 6).

A Educação Patrimonial, por favorecer o conhecimento crítico e a apropriação consciente do patrimônio cultural por parte da sociedade, torna-se um elemento indispensável para a preservação destes bens, facilitando também o diálogo entre a sociedade e os diversos agentes responsáveis pelo patrimônio, possibilitando, por meio da troca de conhecimentos, a formação de parcerias para a proteção e valorização destes bens (HORTA, GRUNBERG; MONTEIRO, 1999, p. 6).

A utilização do patrimônio cultural para uso pedagógico é importante também, pois é mais democrática, uma vez que se trata de uma experiência mais intuitiva do que racional, ou seja, sendo os sentidos os primeiros canais de recepção, qualquer indivíduo pode ter uma experiência repleta de conhecimentos, sem precisar ter um determinado nível de instrução.

Com relação ao campo prático da Educação Patrimonial, defende-se que "[...] todo o espaço que possibilite e estimule, positivamente, o desenvolvimento e as experiências do viver, do conviver, do pensar e do agir conseqüente pode ser tornar um espaço educativo [...]", uma vez que este espaço deixe a passividade transformando-se em um instrumento cultural ativo e dinâmico para o usufruto da sociedade (BRASIL, 2015, p. 7).

O patrimônio cultural como instrumento pedagógico não pode ser usado de forma passiva, apenas como fonte de informação, como um livro didático. Envolve a 'experimentação', assim chamado o uso dos sentidos, aonde se observa, registra-se e explora-se para, por fim, apropriar-se em sua totalidade da capacidade de geração de sentidos daquele bem cultural.

A observação é a primeira etapa na experiência estética e envolve os sentidos como principais canais de recepção. A experimentação do bem patrimonial pela via sensorial deve ser valorizada, pois transcende os limites da razão por meio da intuição. Somente depois do contato com a via sensorial é que o indivíduo passa a submeter essa experiência as suas categorias conceituais, por meio do registro e, logo após, realizar sua análise crítica 
de acordo com seus padrões individuais, onde a exploração do bem patrimonial gera sentidos próprios. A última etapa, da apropriação, requer o envolvimento do indivíduo com o respectivo bem patrimonial, seu reconhecimento e valorização por meio da experiência vivida que provoca sensíveis mudanças no indivíduo que as vivencia. Assim, por meio da interpretação do bem cultural, o sujeito amplia sua capacidade de compreensão do mundo e do meio em que vive, pois todo patrimônio cultural é portador de sentidos. Esse processo de "decodificação" do bem é um dos pilares da Educação Patrimonial (VIANA, 2009, p. 48).

\section{EDUCAÇÃO DO RELIGIOSO}

A Educação do Religioso além do cognitivo está vinculado à questão da experiência em sua origem no termo grego empeiría, significa o “conhecimento de”, mas também como: habilidade, arte, destreza, ciência pratica, com o campo semântico da raiz verbal latina peior (hoje desusado), situado sempre entre dois pólos: o da prova feita ou sofrida, da prova a ser apresentada (OLIVEIRA, 1997, p. 18-21). Se o verbo exterior significa experimentar (provar) e pôr à prova, ele também designa, no procedimento jurídico romano, a ação de servir de prova de seu direito. Portanto, o peritus é o homem entendido em alguma coisa, que tem o domínio de uma prática, e a prática. Assim, o experimentado é qualquer um que deu provas de sua habilidade é ex-peritus (expert). É, portanto, o sujeito que é qualificado pelas provas que ele fornece sobre si mesmo, ou seja, é o conhecimento que ele adquiriu pela experiência que não é absolutamente semelhante a um conhecimento do tipo especulativo, intelectual (VALLE, 1998, p. 36-41).

Aplicando essa distinção ao campo religioso, seria preciso distinguir o expert, cujo conhecimento está fundado numa "prática espiritual” ou ritual de Deus, de quem o simplesmente teólogo e o filósofo teriam apenas um conhecimento intelectual e conceptual (OLIVEIRA, 1997, p. 23-25). Com a educação do religioso espera-se o conhecer para compreender e respeitar a diversidade do fenômeno social que ocorre a partir das diferentes expressões religiosas, podemos dizer que designamos a estrutura especial do homem definida por sistema de relações com os outros homens. Poder-se-ia descrever que o fenômeno religioso como um mundo de estrutura estritamente relacional? Mas como que ou com quem o homem ser relaciona na religião? No fundo de toda a situação verdadeiramente religiosa, encontra-se a referência aos fundamentos últimos do homem: 
quanto à origem, quanto ao fim e quando à profundidade. $\mathrm{O}$ problema religioso toca o homem em sua raiz ontológica. Não se trata de fenômeno superficial, mas implica a pessoa como um todo. Pode caracterizar-se o religioso como zona do sentido da pessoa. Em outras palavras, a religião tem a ver com o sentido último da pessoa, da história, e do mundo (ZILLES, 1991, p. 6-7).

Compreendemos a conceituação de Religião - (latim) Religio como (latim) Relegere (português) Reler - a partir da definição de Cícero que está no livro De natura deorum, escrito em torno no ano 45 a.C., onde representa um modelo complexo da crença tradicional ao culto oficial, onde expressa com clareza uma crítica sobre a doutrina estóica e epicurea ao que refere-se a natureza divina (MESLIN, 1992, p. 33-37). Cícero escreveu:

[...] Não apenas os Filósofos mas também os nossos antepassados distinguiram a supertição da religião. Aqueles que todos os dias rezavam aos deuses e faziam sacrifícios, porque os seus filhos sobreviveram a eles mesmos, foram chamados de superticiosos, palavra que em seguida assumiu um significado mais amplo; invés aqueles que reconsideravam com cuidado e, por dizer, faziam atenção a tudo que referia-se ao culto dos deuses foram chamados de religiosos de relegere, como elegante derivação de eligere (escolha), esmerar de diligere (ter cuidado), inteligente de intelligere (compreender), em todos estes termos o sentido é o mesmo de legere que é o religiosus [...]. (CICERONE, 1998, p. 214, tradução nossa). ${ }^{33}$

Este filósofo propôs que religio é o culto aos deuses segundo os costumes dos ancestrais e que a melhor religião, é a mais antiga, porque está mais próxima dos deuses, é o conjunto de crenças e práticas tradicionais próprias a uma sociedade humana particular, que assim honra seus deuses e merece o respeito das demais comunidades. Um exemplo foi quando os romanos reconheceram aos judeus o direito de praticar livremente em todo o Império seu culto monoteísta a Javé, foi lhes concedido o estatuto jurídico de religio licita. Compreendeu-se muito bem que esse termo religio poderia significar realidades religiosas bastante diferentes, mas qualificava sistemas com coerência de crenças e práticas enraizadas na cultura particular de um povo, e que esse conceito nada tem de exclusivo. Neste sentido que E. Durkein há de retomar, dezoito séculos mais tarde, ao definir religião, na qualidade de sociólogo, como um sistema solidário de crenças e práticas relativas a coisas sagradas (MESLIN, 1992, p. 24-25).

33 De natura deorum, II, 28: [...] non enim philosophi solum, verum etiam maiores nostri superstitionem a religione separaverunt, nam qui totos dies precabantur et immolabant, ut sibi sui liberi superstites essent, superstitiosi sunt appellati quod nomen patuit postea latius; qui autem omnia quae ad cultm deorum pertinerent dilingenter retractarent et tamquam relegerent, (i) sunt dicti religiosi ex relegendo, (tamquam) elegantes ex eligendo, (tamquam) (ex) diligendo diligentes, ex intellegendo intellegentes; his enim in vebis omnibus inest vis legendi eadem quae in religioso [...] 
Portanto, o termo religio, que entre os romanos tinha uma aceitação diferente da atual, designava a realização escrupulosa da observância cultual, no respeito e na piedade devidos aos poderes superiores. Tal observância se fundamenta numa tradição.

Muitas vezes é através da religião que o homem se define no mundo e para com seus semelhantes. É a religião que empresta um sentido e constitui para seus fiéis uma fonte real de informações. Ela funciona como um modelo para o mundo, pois para os crentes a religião orienta as ações e apresenta explicações a questões vitais (De onde vim? Para onde vou? Qual o sentido da existência?), ela fornece respostas também às três ameaças que pesam sobre toda a vida humana: o sofrimento, a ignorância e a injustiça.

A religião pode ser considerada como um comportamento instintivo, característico do homem, cujas manifestações são observadas através dos tempos, em todas as diversas culturas, a partir da busca da compreensão de si mesmo e do mundo, da consideração em relação aos fatos inconsoláveis e desconhecidos.

O ser humano, nos mais diversos cantos do planeta, estruturou a religião e, conseqüentemente, indicou significados ao seu caminhar, para tal foram estabelecidas histórias, ritos e outras formas para retomar o que estaria rompido (SCHLESINGER; PORTO, 1995, p. 2189).

A referência das religiões ao sagrado apresenta uma impressionante variedade de concretizações e mediações. Não existe nenhum acontecimento natural ou vital que não tenha sido sacralizado por alguma cultura. A experiência, fato, fenômeno ou objeto podem ser hirofânicos, isto é, revelador do divino, para os seres humanos em sua busca de transcendência. Portanto o mistério não pode ser explicado, mas apenas tangenciado, as religiões e hierofanias o revelam e ocultam a um só tempo. Desta forma os símbolos religiosos são mediações que nunca conduzem plenamente ao Todo, apenas o sinalizam. Podemos dizer que a maneira como as religiões olham para o sagrado e dela se avizinham é atravessada, assim, por uma ambigüidade intrínseca pela experiência religiosa.

Esta compreensão do religio, seja enquanto conceito da religião, é a experiência religiosa, que pode ser forma íntima ou manifestação exteriorizada, justifica estratégias e objetivos para o Ensino Religioso a partir de um novo itinerário pedagógico (CONSELHO ESTADUAL DE EDUCAÇÃO DE MINAS GERAIS, 1980, p. 12-13). Portanto, consiste na irrupção do sagrado dentro da história, que altera uma seqüência lógica (previsível) para uma direção que só poderá ser entendida posteriormente. 
As condições necessárias a uma correta compreensão do fenômeno religioso são:

$\checkmark$ uso de um instrumento metodológico da maior isenção possível;

$\checkmark$ análise da constância de determinados valores ou credos ao longo do tempo;

$\checkmark$ utilização de documentos primários, leituras interculturais dos documentos primários, evitando qualquer tipo de classificação histórica ou sociológica e não incentivando a apropriação de causa - efeito na tentativa de explicar o momento fundamental do fenômeno religioso.

A partir do processo de visita nos diferentes espaços religiosos permite a compreensão das cosmovisões e expressões que cada comunidade encontra para visibilizar sua leitura de mundo.

\section{ANÁLISE DAS TRÊS EXPERIÊNCIAS A PARTIR DOS REFERENCIAIS DA EDUCAÇÃO PATRIMONIAL E DA EDUCAÇÃO DO RELIGIOSO}

A educação não pode dissociar a experiência de sentido humana presente na história das experiências de sentido religiosas, pois para compreender a identidade do ser humano em sua totalidade faz-se necessário compreender suas articulações míticoreligiosas dentro da diversidade cultural, sendo assim, os espaços sagrados tornam-se essenciais na medida em que fornecem a educação, de maneira privilegiada, as diferentes compreensões que o ser humano tem de si mesmo, do mundo material e espiritual.

Esse processo interpretativo, carregado de significações para a exploração do sentido humano, transforma os espaços sagrados em instrumentos para a compreensão do fenômeno religioso como um todo. Por elucidar as práticas ritualísticas e ser carregados de conhecimentos elementares que permeiam outros conteúdos da área de Ensino Religioso, como espiritualidades, os símbolos religiosos e os textos sagrados, tornam-se importante ferramenta para o desenvolvimento de ações educativas.

Nesse sentido, a educação patrimonial em espaços sagrados refere-se a um processo de trabalho educacional centrado no patrimônio histórico religioso como fonte primária de conhecimento e enriquecimento individual e coletivo. Nobre (2006, p. 20) já salientava o perigo de manter o patrimônio ‘congelado no tempo', pois sem vida cultural projetada no 
presente e direcionada para o futuro, por meio de ofertas culturais e educativas de qualidade até mesmo os espaços repletos de memória podem entrar em decadência.

Nesse sentido, com a preocupação atual a respeito da qualidade da educação na formação do sujeito, base para sua inserção na sociedade, tornando-o capaz não somente de perceber o diferente, mas também de conviver e respeitá-lo, é preciso considerar a diversidade de espaços como importantes instrumentos educativos. É possível perceber, durante as entrevistas, que as atividades foram bem aceitas pela sociedade, apresentando uma demanda superior a que fora projetada inicialmente. Os três entrevistados apontaram que a criação da atividade partiu deles mesmos, sendo que a Trilha e a visita ao cemitério foram desenvolvidas a princípio somente para atender um determinado grupo ou realizar uma atividade solicitada, porém o interesse da sociedade tornou as atividades permanentes.

Todos os entrevistados observaram a necessidade de divulgar o histórico, arquitetura, história dos respectivos espaços que até então passava despercebido aos olhos dos visitantes. Sendo Curitiba uma cidade composta de diferentes manifestações étnicoreligiosas, muitos espaços ficam ocultos na paisagem urbana. Com a realização de práticas de educação patrimonial nesses espaços, é possível expandir o conhecimento, ou seja, levar a informação a todos.

A importância da educação patrimonial é a de ser uma metodologia ampla que pode ser trabalhada com grupos heterogêneos, o que aponta as entrevistas realizadas, uma vez que todos mencionaram não ter um perfil específico de público, trabalhando desde crianças de colo até idosos. Durante a visita, cada indivíduo pode realizar sua própria leitura do espaço e absorver as informações que lhe forem mais interessantes, transformando o passeio em uma aula dinâmica e prazerosa.

Outra questão importante é de abrir os olhos para elementos 'ocultos', ou seja, que passam despercebidos em uma visita sem o processo mediativo. Segundo os entrevistados, a maioria dos participantes se espanta com os detalhes, informações, riqueza de detalhes das obras que até então, não haviam percebido, mesmo já tendo visitado o espaço anteriormente. A compreensão do cenário religioso por parte dos visitantes é um dos principais aspectos que torna a ação educativa de extrema importância para a sociedade, pois permite que os visitantes compreendam melhor como a cidade foi formada, seu desenvolvimento, a compreensão de suas próprias raízes religiosas bem como permite compreender aspectos de outras religiões que também fazem parte da história e do 
cotidiano da cidade.

Apenas a pesquisadora Grassi apontou que não entende a atividade com o propósito de enfoque do cenário religioso, porém, observando toda a sua entrevista é possível compreender que durante a visita no cemitério diversas vezes é mencionado aspectos religiosos que compõem a história do cemitério e das personalidades ali presentes, haja vista que a religião faz parte da dinâmica cultural da sociedade. Nesse sentido, os símbolos e significados são transmitidos para os participantes que compreendem as diferenças entre um cemitério antigo, carregado de imagens religiosas, esculturas e diferentes adereços e percebem as mudanças que as construções cemiteriais passaram ao longo dos anos, e de como as religiões tiveram que se adaptar a isso.

É importante salientar também que a educação patrimonial em espaços sagrados é interdisciplinar, pois engloba conhecimentos históricos, culturais, artísticos e religiosos do local o que torna a atividade importante instrumento de conhecimento e todos os entrevistados apontam essa interdisciplinaridade como o grande ganho cognitivo e afetivo que o participante pode receber e que contribui para as discussões a respeito de uma educação social voltada para a diversidade cultural brasileira. É possível perceber, no caso da Trilha e da visita ao cemitério que o que chama mais a atenção do visitante é exatamente elementos culturais de outras religiões que são distantes de seu cotidiano e essa curiosidade acaba facilitando a difusão do conhecimento da diversidade religiosa existente na cidade.

Por fim, partindo do ideal de não deixar o patrimônio cultural 'congelar' no tempo, dando uma utilidade prática a ele e buscando aproximá-lo da sociedade, todos os entrevistados percebem a importância da utilização do patrimônio para a preservação da memória, para a criação de um sentimento de pertença, para sua preservação e valorização e para criação de um elo entre passado e presente que podem auxiliar tanto na conservação desse bem quanto na difusão do conhecimento. Além disso, conhecer o diversificado patrimônio religioso da cidade permite ao indivíduo respeitar as diferentes manifestações culturais e a melhor compreendê-las. Somente assim é possível aliar conhecimento, ação e preservação.

\section{CONSIDERAÇõES FINAIS}


O espaço sagrado que é produto da consciência religiosa concreta "se apresenta como palco privilegiado das práticas religiosas. Por ser próprio do mundo da percepção, o espaço sagrado apresenta marcas distintivas da religião, conferindo-lhe singularidades peculiares aos mundos religiosos.” (GIL FILHO, 2008, p. 49). Nesse sentido, o espaço sagrado faz parte da construção humana do universo religioso. "Não estando mais num universo meramente físico, o homem vive em um universo simbólico. A linguagem, o mito, a arte e a religião são partes desse universo. São os variados fios que tecem a rede simbólica, o emaranhado da experiência humana." (CASSIRER, 1994, p. 48).

Nesse sentido, a criação de atividades de educação patrimonial envolvendo o espaço sagrado auxilia na transmissão de conhecimentos a respeito da diversidade religiosa desarmando a intolerância de credo por meio da informação. Permite também o reconhecimento de sua identidade cultural e a importância de sua preservação para as futuras gerações, pois faz parte da história da cidade.

As iniciativas demonstradas na pesquisa mostram o interesse da população pela atividade, uma vez que apresentam grande demanda. Com isso, é possível concluir que as pessoas tem curiosidade a respeito da história da própria cidade, das diferentes religiões que fazem parte do cenário urbano e que esse interesse é fundamental para a proteção desse patrimônio.

É importante salientar que esta pesquisa não pretende esgotar o tema proposto, mas sim fornecer uma contribuição teórica importante para o fortalecimento da discussão na área de patrimonialização inserindo o patrimônio religioso como protagonista nas reflexões sobre ação educativa em espaços não-formais. As visitas a esses espaços permitem não apenas conhecer outras realidades, mas perceber e valorizar a grande e rica diversidade cultural, pois a cidadania só se constrói com o reconhecimento e respeito pelas muitas formas de se viver e de se pensar o mundo.

\section{REFERÊNCIAS}

BARRETTO, Margarete. Turismo e legado cultural: as possibilidades do planejamento. Campinas: Papirus, 2000. 96 p.

BRASIL. Ministério da Educação. Educação Patrimonial. Brasília, DF: Programa Mais Educação, 2010. Disponível em: portal.iphan.gov.br/baixaFcdAnexo.do?id=3838. Acesso em 05 abr. 2015 .

CASSIRER, Ernst. Ensaio sobre o homem: introdução a uma filosofia da cultura humana. São Paulo: Martins Fontes, 1994. 
CHOAY, Françoise. A alegoria do patrimônio. São Paulo: Universidade Estadual Paulista, 2001. 282 p.

CICERONE. La natura divina. 4 ed. Milano: Biblioteca Universale Rizzoli, 1998.

CONSELHO ESTADUAL DE EDUCAÇÃO DE MINAS GERAIS. Excerto de parecer sobre o Ensino Religioso nas escolas de $1^{\circ}$ e $2^{\circ}$ graus do Sistema Estadual de Ensino. Belo Horizonte: Mimeo, 1980.

CURITIBA. Prefeitura Municipal. Meio Ambiente. Curitiba: PC, 2017. Disponível em: http://www.curitiba.pr.gov.br/Cidade. Acesso em: 26 maio 2017

FENIANOS, Eduardo Emílio; SADE, Sérgio. Centro, aqui nasceu Kúrýtýba. Curitiba: UniverCidade, 1996. $97 \mathrm{p}$.

GIL FILHO, Sylvio Fausto. Espaço Sagrado: estudos em Geografia da Religião. Curitiba: Ibpex, 2008. $119 \mathrm{p}$.

HORTA, Maria de Lourdes Parreiras; GRUNBERG, Evelina; MONTEIRO, Adriane Queiroz. Guia básico de educação patrimonial. Brasília: Instituto do Patrimônio Histórico e Artístico Nacional, Museu Imperial, 1999. Disponível em:

https://www.facebook.com/catedralcuritiba. Acesso em: 14 jun. 2017.

INSTITUTO DE PESQUISA E PLANEJAMENTO URBANO DE CURITIBA. História do Planejamento. Disponível em: http://www.ippuc.org.br/pensando_a_cidade/. Acesso em: 26 maio 2017.

MESLIN, Michel. A experiência humana do divino: fundamentos de uma antropologia religiosa. Petrópolis: Vozes, 1992.

NOBRE, Cristina. Alvorecer do turismo cultural na primeira metade do século XX: Afonso Lopes Vieira e a valorização do patrimônio da região de Leiria. In:

CONGRESSO TURISMO CULTURAL TERRITÓRIOS E IDENTIDADES. [Leiria], 30 nov. 2006. Disponível em:

https://iconline.ipleiria.pt/bitstream/1040o.8/611/1/Alvorecer\%20do\%2oturismo\%20cul tural_CN.pdf. Acesso em: 29 dez. 2019.

OLIVEIRA, Francisco Arsego de. A experiência de Deus. Pelotas: Educat, 1997.

SANTANA, Mariely. Patrimônio, turismo e identidade cultural. Bahia, análise e dados:

Revista da Superintendência de Estudos Econômicos e Sociais da Bahia, Salvador, v.11, n.2, p. 169-173, set. 2001.

SANTOS, Fausto Henrique dos. Metodologia aplicada em museus. São Paulo: Mackenzie, 2001. 225 p.

SCHLESINGER, Hugo; PORTO, Humberto. Dicionário Enciclopédico das Religiões. v. 2. Petrópolis: Vozes, 1995. 
SOUZA FILHO, Carlos Frederico Marés. Bens culturais e sua proteção jurídica. Curitiba: Juruá, 2005. 177 p.

VALLE, Edênio. Experiência religiosa: enfoque psicológico. In: BRITO, Ênio José da Costa; GORGULHO, Gilberto da Silva. (org.). Religião ano 2000. São Paulo: Loyola, 1998.

VIANA, Uhelinton Fonseca. Patrimônio e educação: desafios para o processo de ensino e aprendizagem. 2009. Dissertação (Mestrado em Educação) - Centro de Pós-Graduação em Educação, Universidade Federal Fluminense, Niterói, 2009.

ZILLES, Urbano. Filosofia da religião. São Paulo: Paulinas, 1991.

Recebido em: 08.o8.2018 Aprovado em: 13.09.2019 